\title{
IMPORTÂNCIA DA FISIOTERAPIA NO TRATAMENTO DE FRATURA DE COLO DE FÊMUR EM IDOSOS ACIMA DE 60 ANOS
}

Renilce Rodrigues Ferreira Francisco Carlos Santos Cerqueira
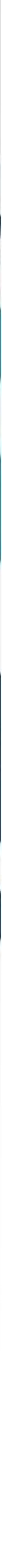


\section{IMPORTÂNCIA DA FISIOTERAPIA NO TRATAMENTO DE FRATURA \\ DE COLO DE FÊMUR EM IDOSOS ACIMA DE 60 ANOS}

Renilce Rodrigues Ferreira Francisco Carlos Santos Cerqueira

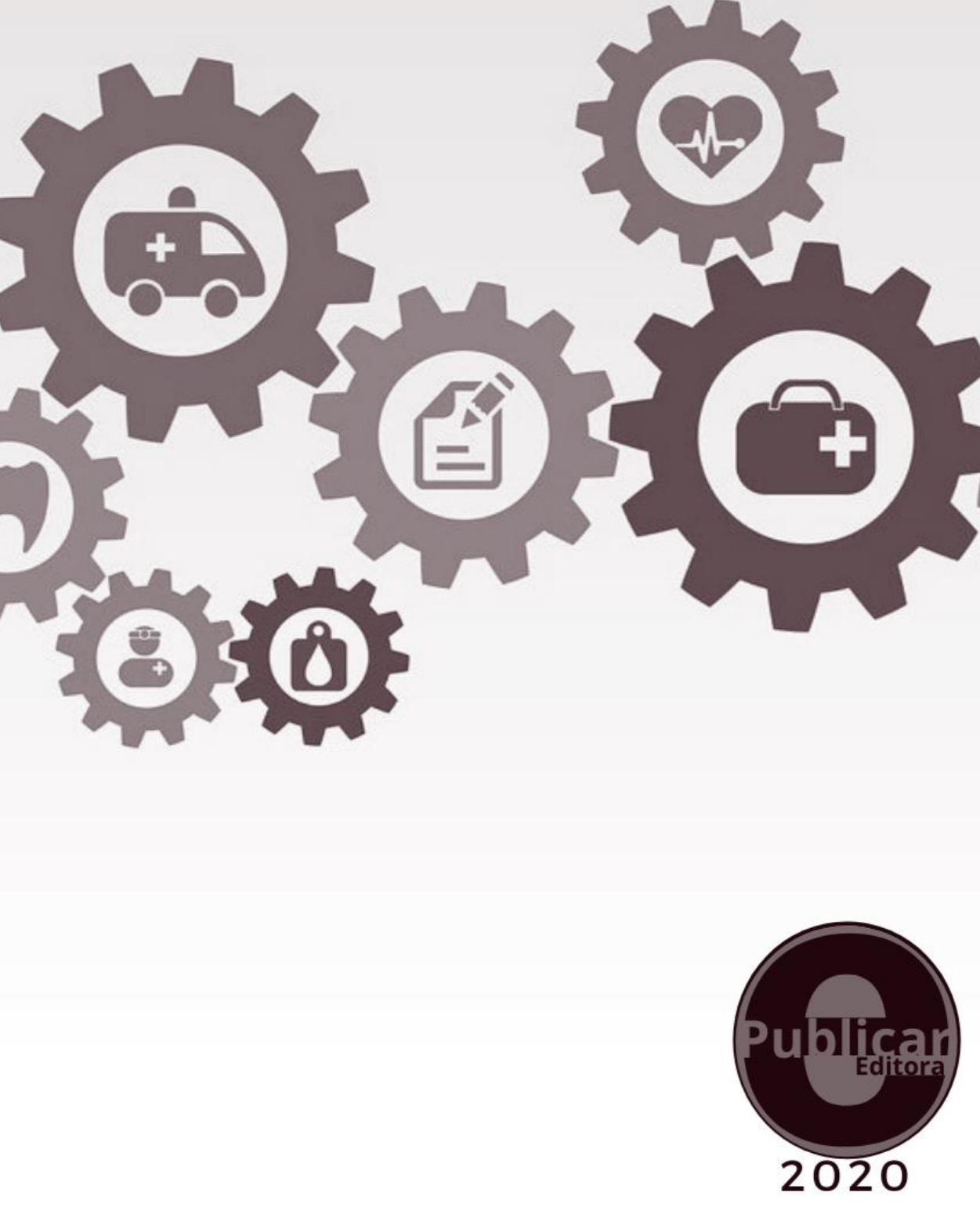


2020 by Editora e-Publicar

Copyright (C) Editora e-Publicar

Copyright do Texto (C) 2020 Os autores

Copyright da Edição (C) 2020 Editora e-Publicar

Direitos para esta edição cedidos à Editora e-Publicar pelos autores.

Editora Chefe

Patrícia Gonçalves de Freitas

Editor

Roger Goulart Mello

Diagramação

Roger Goulart Mello

Projeto gráfico e Edição de Arte

Patrícia Gonçalves de Freitas

Revisão

Os Autores

Todo o conteúdo dos artigos, dados, informações e correções são de responsabilidade exclusiva dos autores. O download e compartilhamento da obra são permitidos desde que os créditos sejam devidamente atribuídos aos autores. É vedada a realização de alterações na obra, assim como sua utilização para fins comerciais.

A Editora e-Publicar não se responsabiliza por eventuais mudanças ocorridas nos endereços convencionais ou eletrônicos citados nesta obra.

\section{Conselho Editorial}

Dr ${ }^{\mathrm{a}}$ Cristiana Barcelos da Silva - Universidade Estadual do Norte Fluminense Darcy Ribeiro

Dr ${ }^{\mathrm{a}}$ Elis Regina Barbosa Angelo - Pontifícia Universidade Católica de São Paulo

Dr. Rafael Leal da Silva - Universidade Federal do Rio Grande do Norte

Dr. Fábio Pereira Cerdera - Universidade Federal Rural do Rio de Janeiro

Dr $^{\mathrm{a}}$ Danyelle Andrade Mota - Universidade Tiradentes

Me. Doutorando Mateus Dias Antunes - Universidade de São Paulo

Me. Doutorando Diogo Luiz Lima Augusto - Pontifícia Universidade Católica do Rio de Janeiro

Me. Doutorando Francisco Oricelio da Silva Brindeiro - Universidade Estadual do Ceará

$M^{a}$ Doutoranda Bianca Gabriely Ferreira Silva - Universidade Federal de Pernambuco

Ma Doutoranda Andréa Cristina Marques de Araújo - Universidade Fernando Pessoa

Me. Doutorando Milson dos Santos Barbosa - Universidade Tiradentes

$\mathrm{M}^{\mathrm{a}}$ Doutoranda Jucilene Oliveira de Sousa - Universidade Estadual de Campinas

$\mathrm{M}^{\mathrm{a}}$ Doutoranda Luana Lima Guimarães - Universidade Federal do Ceará

$\mathrm{M}^{\mathrm{a}}$ Cristiane Elisa Ribas Batista - Universidade Federal de Santa Catarina 
$\mathrm{M}^{\mathrm{a}}$ AndrelizeSchabo Ferreira de Assis - Universidade Federal de Rondônia

Me.DanielOrdane da Costa Vale - Pontifícia Universidade Católica de Minas Gerais

Me.Glaucio Martins da Silva Bandeira - Universidade Federal Fluminense

Me. Jose Henrique de Lacerda Furtado - Instituto Federal do Rio de Janeiro

M ${ }^{a}$ Luma Mirely de Souza Brandão - Universidade Tiradentes

Dr ${ }^{\mathrm{a}}$. Rita Rodrigues de Souza - Universidade Estadual Paulista

Dr. Helio Fernando Lobo Nogueira da Gama - Universidade Estadual De Santa Cruz

Dr. Willian Douglas Guilherme - Universidade Federal do Tocantins

Dr ${ }^{\text {a }}$. Naiola Paiva de Miranda - Universidade Federal do Ceará

Dr ${ }^{\mathrm{a}}$. Dayanne Tomaz Casimiro da Silva - UFPE - Universidade Federal de Pernambuco

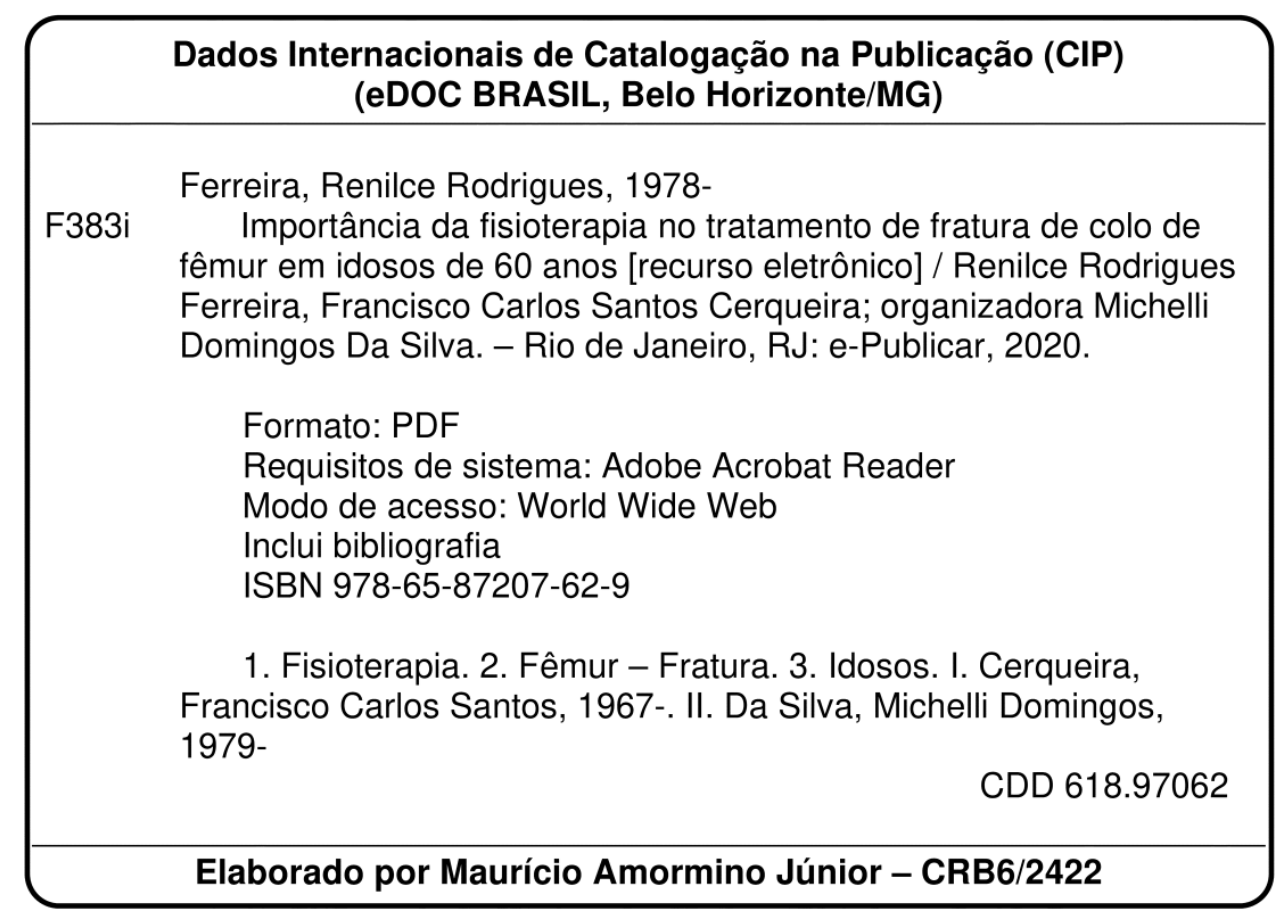

Editora e-Publicar

Rio de Janeiro - RJ - Brasil

contato@editorapublicar.com.br

$\underline{\text { www.editorapublicar.com.br }}$ 


\section{APRESENTAÇÃO}

É com imensa satisfação que apresentamos a obra "Importância da fisioterapia no tratamento de fratura de colo de fềmur em idosos de 60 anos" elaborada por Renilce Rodrigues Ferreira, Francisco Carlos Santos Cerqueira e organizada por Michelli Domingos da Silva.

Desejamos a todos uma excelente leitura!

Patrícia Gonçalves de Freitas Roger Goulart Mello Editora e-Publicar 


\section{Sumário}

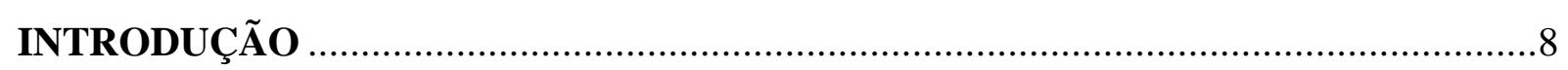

METODOLOGIA

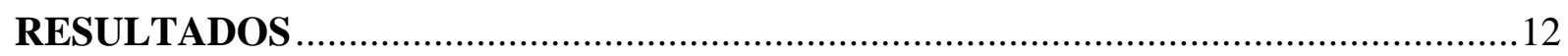

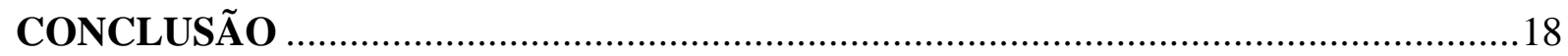




\section{RESUMO}

Introdução: o envelhecimento é algo que não podemos reverter, no Brasil estima-se que a população de idosos daqui a 50 anos irá crescer de forma significativa, o envelhecimento populacional e com ele vem o aumento de doenças crônicas como a hipertensão, diabetes, osteoporose, Parkinson entre outras decorrentes do envelhecimento ocasionando a incapacidade funcional, aumentando os riscos de quedas/fraturas diminuindo a capacidade da pessoa idosa. Objetivo: investigar quais os tratamentos propostos pela fisioterapia para as fraturas proximais do fêmur em idosos submetidos a reparo cirúrgico, por meio de uma revisão de literatura. Metodologia: O presente estudo trata-se de uma pesquisa exploratória do tipo revisão de literatura. A realização das buscas foi através da Biblioteca Virtual em Saúde (BVS), Literatura Latino Americana e do Caribe em Ciências da Saúde (Lilacs) e Scientific Eletronic Library Online (Scielo) sobre a temática. Compreendendo o período de 2013 a 2020. Critérios de inclusão: artigos em português e gratuitos, e critérios de exclusão: outros idiomas, pagos.Resultados: as literaturas registram a importância da fisioterapia durante pós cirúrgicos onde $40 \%$ dos pacientes têmresultados positivos neste tipo de fratura. Esse processo tende a motivar e/ou acentuar conflitos intrafamiliares. Porém, são capazes de motivar um cuidado mais humano com esse idoso. Conclusão: $O$ tratamento fisioterapêutico pode ser necessário em qualquer fase da vida, porém no idoso tem uma relevância não só de tratamento, mas também de prevenção e intervenção, o que ajuda na melhora da qualidade de vida. Viabilizar a saúde junto aos idosos deve tornar-se um habito constante, por isso, é de suma importância o acompanhamento de um profissional qualificado atuando na terceira idade, promovendo praticas preventivas de exercícios físicos.

Palavras-chaves: Fisioterapia; Fratura; Cirurgia; Idosos; Queda. 


\section{INTRODUÇÃO}

O envelhecimento é algo que não podemos reverter, no Brasil estima-se que a população de idosos daqui a 50 anos irá crescer de forma significativa o envelhecimento populacional e com ele vem o aumento de doenças crônicas como a hipertensão, diabetes, osteoporose, Parkinson entre outras decorrentes do envelhecimento ocasionando a incapacidade funcional aumentando os riscos de quedas/fraturas diminuindo a capacidade da pessoa idosa (FERNANDES et al., 2016).

Idosos enfrentam obstáculos em todos os lugares frequentados, pode ser em bares, lanchonetes, supermercados e hospitais. Com o período de tempo é comum que fiquemos mais frágeis e rúpteis, afinal acontece à perda de massa muscular os ossos ficam mais delicados e o ser humano se sente mais enfermo, com isso os índices de escorregões e pisar em lugares de forma desequilibrada e as quedas aumenta trazendo consequências como as fraturas ósseas ficar letárgico e possuir ulcerações (GASPAROTTO et al., 2014).

É de suma importância que os indivíduos, tantos parentes como trabalhadores, não apenas da área da saúde em outros estabelecimentos de domínio público ou que não tenham o conhecimento de quão grave se torna quedas tão pequenas de lugares baixos pôr o idoso, não possuir força e sem força não a equilíbrio e sem equilíbrio a queda se torna pior. Cair de forma desordenada traz consequências terríveis e irreversíveis (BARBOSA et al., 2017).

É concordado que para poder diminuir os índices de quedas em idosos sejam vistos primeiro o que estão causando esse baque, para que seja corrigido e levar a fundo para descobrir o que estão fazendo de errado nas residências ou fora delas. É importante salientar que a primeira queda em um idoso pode não ser tão grave, mas a consequências delas sim (CHEHUEN NETO et al., 2018).

A vida dos idosos que estão habituados a ter certa individualidade e a não dependência de familiares e amigos perder essa autonomia, para eles é algo tenebroso com isso a tristeza e o medo depois de uma queda que trouxe algum tipo de problema de saúde faz com que eles saem com menos frequência de casa se sentindo cada vez mais dependente e incapaz, muitas das vezes ocasionando depressão e síndrome do medo de cair (MORSCH et al., 2016).

O idoso se torna uma pessoa incapaz e passa a não se locomover sozinho ou fazer coisas de rotinas que ele costumava fazer isso deixa muitas das vezes amargurados e se sentindo desqualificados. Alguns fatores como a dor constante em um local do corpo onde ele pode ter batido durante algum tombo e essa mesma dor faz com que ele perca a vontade de 
fazer o que fazia antes, caminhar ou praticar exercícios físicos o fazendo ser uma pessoa sedentária acarretando ainda mais problemas na saúde (OLIVEIRA et al.,2014).

É considerável dizer que isto é um caso de Saúde Pública e alertar o profissional ou a família que a queda do mesmo pode prolongar a sua estadia em hospitais ou residências trazendo problemas maiores, por isso é fundamental a orientação da necessidade da retirada de objetos como tapetes e o uso de sandálias ou sapatos que traga a dificuldades de se locomover. Orientar para a localização de móveis para que fique mais fácil o acesso para outros cômodos da casa (ABREU et al., 2016).

Os idosos depois de suportar de forma resinada e por não poder aproveitar a vida como eles costumavam usufruir na juventude ligando a velhice como algo extremamente ruim trazendo para si um estado de trauma, para a sua locomoção perdendo a vontade e o ânimo para sair de casa piorando ainda mais a forma do mesmo se locomover, pois a fixação pra olhar onde pisa pelo o medo de cair e piorar ainda mais a sua forma de viver(GOMES et al., 2013).

Essa fixação de olhar por onde anda, pode ocasionar dorsalgia por ficar muito tempo curvado, alguns medicamentos também podem contribuir para o ocorrido é importante analisar os efeitos colaterais antes de fazer o uso deles para melhor o uso. Alguns idosos apenas deixam para falar sobre a queda que sofreu depois que ela já lhe causou diversos problemas e dores agressivas, até mesmo chegam a pensar que a dor no local da queda é uma dor do envelhecimento e destacando o trauma (FREITAS et al.,2015).

Por ser a fratura do quadril e fêmur um problema de saúde pública, pesquisas na área podem impactar no prognóstico dessa doença, reduzindo suas complicações e aumentando a expectativa e qualidade de vida dos pacientes. Além disto, a incidência de fraturas de fêmur entre os idosos aumentará com o envelhecimento da população, resultando em um ônus econômico crescente. Como demonstrado, diversos estudos sugerem vantagens da implementação de um modelo multidisciplinar de cuidados para pacientes idosos com fraturas do quadril.

No Brasil, apesar de estarem disponíveis na literatura muitos estudos sobre osteoporose, não foi encontrado nenhum a respeito do custo-efetividade da implantação de unidades multidisciplinares para o tratamento do idoso com fratura osteoporótica de fêmur. Atualmente, o processo de envelhecimento populacional observado no mundo é fato marcante em todas as sociedades. Tal processo é definido como a mudança na estrutura etária da 
população, o que leva a um aumento relativo da quantidade de pessoas acima de determinada idade, considerada como definidora do início da velhice. No Brasil, é definido como idoso o indivíduo que tem 60 anos de idade ou mais.

Diversos aspectos contribuem para o aumento na expectativa de vida como melhores condições sociais e de saneamento, uso de antibióticos e de vacinas, que influenciam diretamente na qualidade de vida. A pesquisa é importante por que no seu bojo traz novas informações para a problemática em questão. A Fisioterapia tem um papel fundamental na reabilitação no pós-operatório da fratura de fêmur em idosos, a fim de prevenir e tratar as alterações funcionais que ocorrem devido a esse trauma. São vários os exercícios e meios terapêuticos para se trabalhar diversos fatores como mobilidade.

Força muscular, equilíbrio postural, coordenação motora, propriocepção, marcha, dentre outros. A fratura no colo do fêmur é encontrada frequentemente na população acima de 60 anos de idade e ocorre, na maioria das vezes, por trauma de baixa energia, especialmente em queda da própria altura. A sintomatologia caracteriza-se por dor no quadril acometido, que pode irradiar-se para a coxa e o joelho.

Nesse contexto supramencionado a pesquisa é relevante uma vez que o resultado trás novo conhecimento a respeito do assunto em pauta, também contribui de forma positiva na mudança de comportamento dos idosos que passou por esse processo. Metodologia: Este trabalho é uma pesquisa pra verificar quais os tratamentos propostos pela Fisioterapia para as fraturas proximais do fêmur em idosos submetidos a reparo cirúrgico, por meio de uma revisão de literatura. Diante desse fato, por que a Fisioterapia no tratamento de fratura de colo de fêmur em idosos a pós a cirurgia é importante?

O presente artigo tem como escopo investigar quais os tratamentos propostos pela fisioterapia para as fraturas proximais do fêmur em idosos submetidos a reparo cirúrgico, por meio de uma revisão de literatura. 


\section{METODOLOGIA}

O presente estudo trata-se de uma pesquisa exploratória do tipo revisão de literatura. A pesquisa exploratória visa proporcionar ao pesquisador uma maior familiaridade com o problema em estudo. Este tipo de pesquisa tem como meta tornar um problema complexo mais explícito ou mesmo construir hipóteses mais adequadas.

A realização das buscas foi através da Biblioteca Virtual em Saúde (BVS), Literatura Latino Americana e do Caribe em Ciências da Saúde (Lilacs) e Scientific Eletronic Library Online (Scielo) sobre a temática. Compreendendo o período de 2013 a 2020. Critérios de inclusão: artigos em português e gratuitos, e critérios de exclusão: outros idiomas, pagos.

Segundo Gil (2017) a base de coleta de dados consiste em identificar, ordenar e estabelecer as informações contidas nos tipos de leitura proposta e seguirá as seguintes premissas: Leitura exploratória de todo material selecionado (leitura rápida); Leitura seletiva (leitura aprofundada); Leitura interpretativa (registro de informações extraídas das fontes como autores, ano, resultados e conclusões). 


\section{RESULTADOS}

A seleção inicial dos trabalhos ocorreu pela leitura dos títulos e resumos de todos os trabalhos encontrados. Seguindo os critérios de inclusão e exclusão, a partir da leitura dos títulos e resumos dos 475 artigos, e a seguir foram selecionados 5 artigos.

Quadro - Síntese dos artigos selecionados para esta revisão integrativa.

\begin{tabular}{|c|c|c|c|c|}
\hline AUTOR/ANO & $\begin{array}{c}\text { OBJETIVO } \\
\text { DO } \\
\text { ESTUDO }\end{array}$ & $\begin{array}{l}\text { TIPO DE } \\
\text { ESTUDO }\end{array}$ & METODOLOGIA & RESULTADOS \\
\hline $\begin{array}{l}\text { BARREIRA, } \\
2015 .\end{array}$ & $\begin{array}{l}\text { Conhecer as } \\
\text { consequênci } \\
\text { as na } \\
\text { capacidade } \\
\text { funcional } \\
\text { do idoso } \\
\text { vítima de } \\
\text { queda, da } \\
\text { qual resulte } \\
\text { fratura da } \\
\text { extremidade } \\
\text { proximal do } \\
\text { fêmur. }\end{array}$ & $\begin{array}{l}\text { Descritivo, } \\
\text { longitudina } \\
\text { l, } \\
\text { correlacion } \\
\text { al, } \\
\text { prospectivo } \\
\text { e } \\
\text { quantitativ } \\
\text { o. }\end{array}$ & $\begin{array}{l}\text { A amostra englobou } 35 \text { idosos na } \\
\text { primeira avaliação e } 30 \text { na } \\
\text { segunda, utentes internados no } \\
\text { serviço de traumatologia da } \\
\text { Unidade Hospitalar de Bragança. } \\
\text { A colheita de dados ocorreu entre } \\
\text { fevereiro e junho de } 2014 \text { e a } \\
\text { segunda avaliação foi realizada } \\
\text { entre agosto e dezembro de } 2014 \text {. } \\
\text { Pretendeu-se avaliar o grau de } \\
\text { recuperação da capacidade } \\
\text { funcional após fratura da } \\
\text { extremidade proximal do fêmur, o } \\
\text { medo de cair e caracterizar as } \\
\text { quedas. Os idosos incluílos na } \\
\text { amostra foram selecionados com } \\
\text { base nos seguintes critérios de } \\
\text { inclusão: idade igual ou superior a } \\
\text { 65 anos; clinicamente estáveis; } \\
\text { capacidade de entender e marcha } \\
\text { independente ou com o auxílio de } \\
\text { meios auxiliares de marcha } \\
\text { (bengala, tripé, canadiana). São } \\
\text { critérios de exclusão: doenças } \\
\text { neuropsiquiátricas ou déficit } \\
\text { cognitivo grave e condição médica } \\
\text { instável. }\end{array}$ & $\begin{array}{l}\text { Da amostra estudada } \\
33,3 \% \text { apresentaram } \\
\text { fratura do colo do fêmur } \\
\text { as restantes } 66,6 \% \\
\text { apresentaram fraturas } \\
\text { trocantéricas, } \\
\text { subtrocantéricas } \\
\text { intertrocantéricas. Fo } \\
\text { instituído tratamento } \\
\text { cirúrgico em 93,3\%. Os } \\
\text { valores do índice de Katz } \\
\text { diminuíram de 15,53 para } \\
12,93 \text { pontos. O grau de } \\
\text { recuperação } \\
\text { independência funcional } \\
\text { significativamente maior } \\
\text { em doentes que realizaram } \\
\text { osteossíntese com prótese } \\
\text { da anca, seja ela total ou } \\
\text { parcial. }\end{array}$ \\
\hline $\begin{array}{l}\text { CARNEIRO; } \\
\text { ALVES; } \\
\text { MERCADAN } \\
\text { TE, } 2013 \text {. }\end{array}$ & $\begin{array}{l}\text { Realizar } \\
\text { uma revisão } \\
\text { sistemática } \\
\text { sobre } \\
\text { protocolos } \\
\text { de } \\
\text { fisioterapia } \\
\text { no pós- } \\
\text { operatório } \\
\text { de fraturas } \\
\text { proximais } \\
\text { de fêmur } \\
\text { em idosos. }\end{array}$ & $\begin{array}{l}\text { Revisão de } \\
\text { Literatura }\end{array}$ & $\begin{array}{l}\text { Para a busca utilizou-se as bases de } \\
\text { dados MedLine e PubMed. Os } \\
\text { critérios de inclusão foram estudos } \\
\text { publicados nos últimos } 10 \text { anos, } \\
\text { nos idiomas inglês e português, } \\
\text { realizados em seres humanos, sem } \\
\text { distinção de gênero e com } \\
\text { indivíduos de idade maior que } 60 \\
\text { anos que sofreram fratura proximal } \\
\text { de fêmur tratadas com } \\
\text { osteossíntese. Foram encontrados } \\
1.428 \text { artigos, destes foram } \\
\text { selecionados 54 artigos para leitura } \\
\text { na íntegra. Â partir desta leitura, } \\
40 \text { trabalhos foram exclusos, sendo }\end{array}$ & 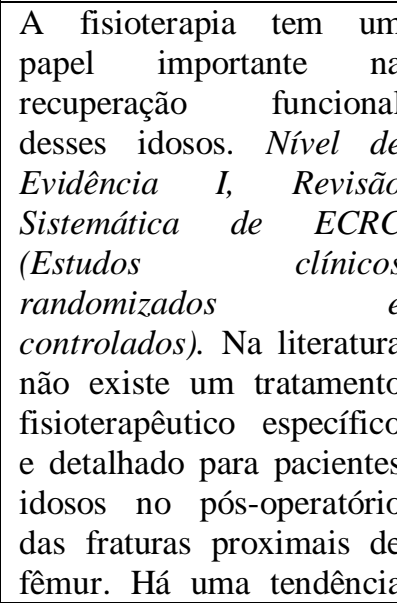 \\
\hline
\end{tabular}




\begin{tabular}{|c|c|c|c|c|}
\hline & & & 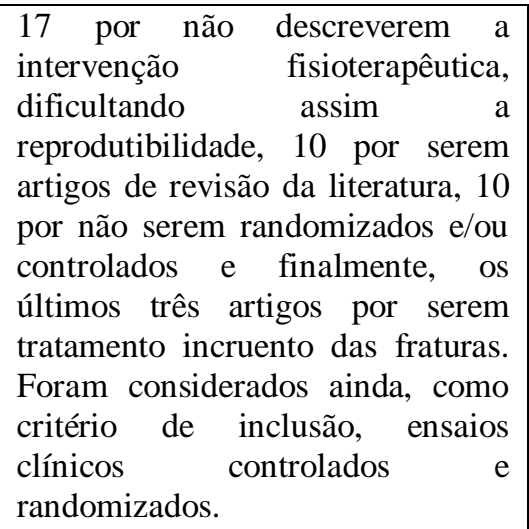 & $\begin{array}{l}\text { de que os exercícios de } \\
\text { fortalecimento seriam a } \\
\text { chave para melhora } \\
\text { funcional destes pacientes. } \\
\text { As evidências mostram que } \\
\text { a fisioterapia tende a } \\
\text { acelerar a recuperação do } \\
\text { idoso, mas ainda não é } \\
\text { garantia o retorno deste ao } \\
\text { seu estado funcional pré- } \\
\text { fratura. }\end{array}$ \\
\hline $\begin{array}{l}\text { CHANG et al. } \\
2016\end{array}$ & $\begin{array}{l}\text { Verificar a } \\
\text { medida da } \\
\text { autoeficácia } \\
\text {, efeito do } \\
\text { programa } \\
\text { de } \\
\text { exercícios } \\
\text { em } \\
\text { pacientes } \\
\text { com fratura } \\
\text { de fêmur, e } \\
\text { o efeito de } \\
\text { medida foi } \\
\text { diferente } \\
\text { em relação } \\
\text { aos grupos } \\
\text { de idade e } \\
\text { sexo. }\end{array}$ & $\begin{array}{l}\text { Trata-se de } \\
\text { um ensaio } \\
\text { controlado } \\
\text { e } \\
\text { randomiza } \\
\text { do. }\end{array}$ & $\begin{array}{l}232 \text { pacientes foram selecionados, } \\
\text { idade entre } 79+-9,4 \text { anos, com } \\
\text { fratura de quadril. Foram } \\
\text { aleatoriamente designados para } \\
\text { grupo intervenção (n=120) e } \\
\text { controle }(\mathrm{n}=112) \text {. Foi feito um } \\
\text { programa de exercícios } \\
\text { funcionalmente orientado para } \\
\text { casa. Os dados foram coletados no } \\
\text { início do estudo, pós-intervenção } \\
\text { (6 meses), e follow-up (9 meses). } \\
\text { As variáneis primárias para este } \\
\text { estudo incluem o relato do } \\
\text { paciente sobre a mobilidade básica } \\
\text { e da atividade diária e autoeficácia } \\
\text { funcional. }\end{array}$ & 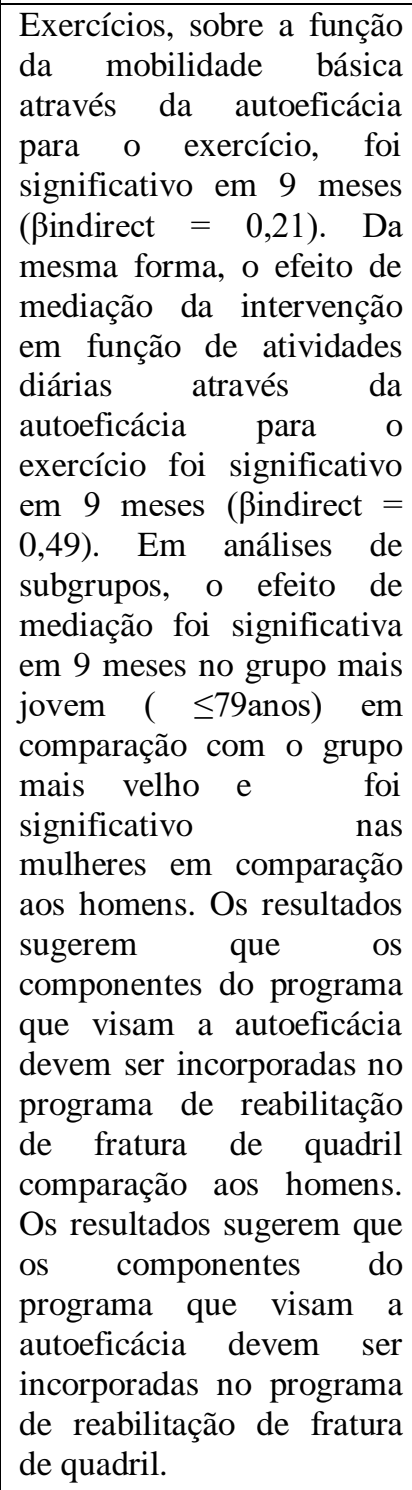 \\
\hline $\begin{array}{l}\text { KRONBORG } \\
\text { et al. } \\
2014 \text {. }\end{array}$ & $\begin{array}{l}\text { analisar a } \\
\text { viabilidade } \\
\text { do hospital } \\
\text { no } \\
\text { treinamento } \\
\text { de força } \\
\text { progressiva } \\
\text { implementa }\end{array}$ & $\begin{array}{l}\text { Foi } \\
\text { utilizado o } \\
\text { mini } \\
\text { mental para } \\
\text { a avaliação } \\
\text { da } \\
\text { cognição. }\end{array}$ & $\begin{array}{l}\text { Um programa diário com } 36 \\
\text { pacientes (durante a semana) de } \\
\text { treinamento de força de extensão } \\
\text { de joelho progressiva para o } \\
\text { membro fraturado, usando pesos } \\
\text { de tornozelo em } 3 \text { conjuntos de } \\
\text { cargas máximas de } 10 \text { repetições. } \\
\text { O desfecho primário foi a mudança }\end{array}$ & $\begin{array}{l}\text { O treinamento de força foi } \\
\text { iniciado em uma média de } \\
2,4 \quad(0,7) \text { dias após a } \\
\text { cirurgia. As cargas de } \\
\text { treinamento (quilogramas } \\
\text { levantadas) aumentaram } \\
\text { de1,6(0,8)para4,3(1,7)kgm } \\
\text { aisde }\end{array}$ \\
\hline
\end{tabular}




\begin{tabular}{|c|c|c|c|c|}
\hline & $\begin{array}{l}\text { do na ala } \\
\text { aguda após } \\
\text { cirurgia de } \\
\text { fratura de } \\
\text { fêmur com } \\
\text { base em } \\
\text { critériospré- } \\
\text { especificad } \\
\text { os. }\end{array}$ & & $\begin{array}{l}\text { na carga de treinamento }(\mathrm{kg}) \\
\text { durante a extensão de joelho no } \\
\text { treinamento de força. Os desfechos } \\
\text { secundários foram alterações na } \\
\text { dor relacionada com a fratura } \\
\text { dequadril. }\end{array}$ & $\begin{array}{l}4,3 \text { sessões }(2.2) \text { de } \\
\text { treinamento }(\mathrm{P}, 0,001) \text {. A } \\
\text { força em extensão } \\
\text { isométrica máxima de } \\
\text { joelho aumentou de } 0,37 \\
(0,2) 0,61 \text { (0,3) Nm } \\
\mathrm{kg}(\mathrm{P}, 0,001) \text {, } \\
\text { enquanto o déficit médio } \\
\text { de força no membro } \\
\text { fraturado diminuiu de } 50 \% \\
\text { para } 32 \% \text { na não } \\
\text { fraturado, P, 0,001). } \\
\text { Apenas } 3 \text { de } 212 \text { sessões } \\
\text { não foram realizadas por } \\
\text { causa da dor relacionada à } \\
\text { fratura de quadril. O } \\
\text { treinamento progressivo de } \\
\text { força em extensão de } \\
\text { joelho no membro } \\
\text { fraturado na fase aguda, } \\
\text { pode reduzir assimetria de } \\
\text { força entre os membros. A } \\
\text { eficácia clínica necessita } \\
\text { de confirmação em um } \\
\text { projeto em } \\
\text { controladorandomizado. }\end{array}$ \\
\hline $\begin{array}{l}\text { WOODWAR } \\
\text { D et al. } 2014 .\end{array}$ & $\begin{array}{l}\text { Determinar } \\
\text { a extensão } \\
\text { na qual o } \\
\text { gênero } \\
\text { influenciou } \\
\text { o resultado } \\
\text { funcional e } \\
\text { resposta ao } \\
\text { exercício } \\
\text { em pessoas } \\
\text { após fratura } \\
\text { de fêmur. }\end{array}$ & $\begin{array}{l}\text { Questionári } \\
\text { o de Estado } \\
\text { Mental } \\
\text { para } \\
\text { avaliação } \\
\text { cognitiva. }\end{array}$ & $\begin{array}{l}\text { Fizeram parte desse estudo } 160 \\
\text { participantes, sendo, } 30 \text { homens e } \\
130 \text { mulheres. Os participantes } \\
\text { foram recrutados em } 3 \text { unidades de } \\
\text { reabilitação em Sydney na } \\
\text { Austrália, após fixação cirúrgica } \\
\text { da fratura de fêmur. Os critérios de } \\
\text { inclusão foram: capacidade de } \\
\text { descarga de peso parcial ou total, } \\
\text { conseguir andar com ou sem ajuda } \\
\text { de uma pessoa e/ou dispositivo de } \\
\text { apoio e não possuir restrições } \\
\text { médicas para o exercício. Os } \\
\text { participantes foram divididos em } 2 \\
\text { grupos aleatóriamente. O } 1^{\circ} \text { grupo: } \\
\text { realizaram } \\
\text { exercíciosmaispesadosemaisintens } \\
\text { oseo2 } 2^{\circ} \\
\text { grupo: realizaram exercícios } \\
\text { mais leves e moderados. Os } \\
\text { participantes do grupo } 1 \text {, } \\
\text { realizaram exercícios } 2 \text { vezes ao } \\
\text { dia, } 60 \text { minutos de exercícios, por } \\
16 \text { semanas. Os exercícios do } \\
\text { grupo } 1 \text {, consistisiam em andar, } \\
\text { pisar em direções diferentes, } \\
\text { levantar-se e sentar-se. Os } \\
\text { participantes do grupo } 2 \text {, } \\
\text { realizaram exercícios deitados e } \\
\text { sentados, } 1 \text { vez por dia, } 30 \text { minutos } \\
\text { de exercícios por } 4 \text { semanas. }\end{array}$ & $\begin{array}{l}\text { Os dados dos resultados } \\
\text { estavam disponíveis para } \\
160 \text { participantes, } 30 \\
\text { homens (19\%) e 130 } \\
\text { mulheres }(81 \%) \text { no início } \\
\text { do estudo, com a retirada } \\
\text { de } 4 \text { homens (13\%) e } 6 \\
\text { mulheres (5\%) na } 16^{\mathrm{a}} \\
\text { semana. Não houve } \\
\text { diferenças de gênero para } \\
\text { qualquer linha de base } \\
\text { medida ou para a maioria } \\
\text { das } 19 \text { medidas de } \\
\text { resultados funcionais na } 4^{\mathrm{a}} \\
\text { e } 16^{\mathrm{a}} \text { semanas. Na } 4^{\mathrm{a}} \\
\text { semana, homens tiveram } \\
\text { melhor desempenho na } \\
\text { força extensora do joelho } \\
\text { (2,1 kg, IC 95\%0,6- } 3,7, \\
\text { p <0,01). Esta } \\
\text { diferençanão persistiu após } \\
\text { o ajuste para peso do } \\
\text { corpo, no entanto, persistiu } \\
\text { após o ajuste para a linha } \\
\text { de base, a cognição e a } \\
\text { idade (p = 0,038). Na } 4^{\mathrm{a}} \\
\text { semana, homens tiveram } \\
\text { melhor desempenho na } \\
\text { estabilidade } \\
\text { coordenada } \\
(10,0 \text { pontuação } \\
\text { de erro, 95\% -17,6 CI para } \\
-2,4 \text {, p = 0,010) e este } \\
\text { persistiu após o ajuste para }\end{array}$ \\
\hline
\end{tabular}




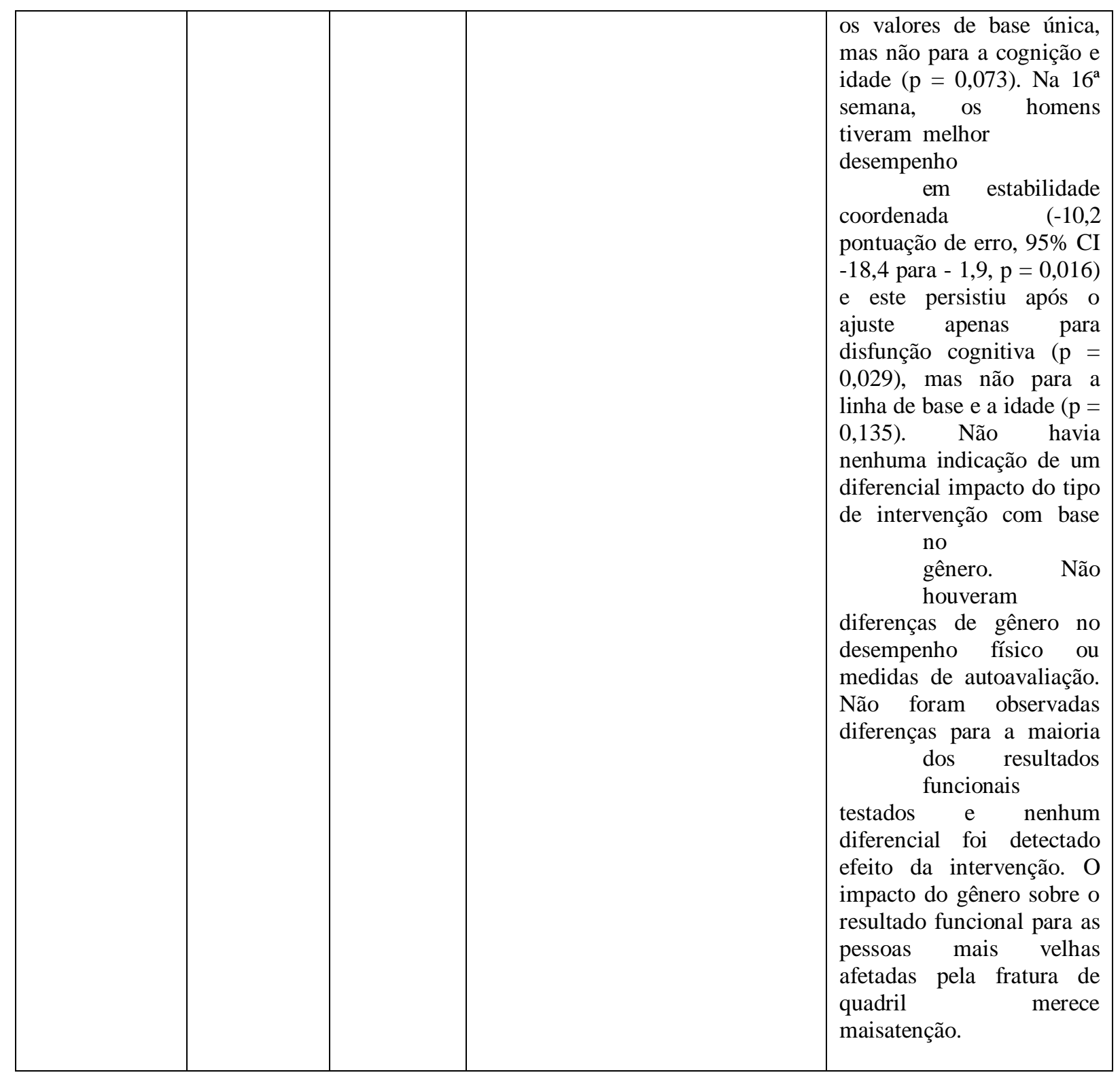

Os artigos selecionados vieram comprovar que a fisioterapia tem um fator primordial na reabilitação do paciente, precisamos estar atentos no que interfere na vida e na sua evolução. Os idosos analisando a sua projeção ascendente a cada década, vem mostrando uma alta incidência de internações por fratura de fêmur neste grupo etário que muitas vezes permanece por um tempo maior hospitalizado, sendo que muitos destes evoluem para o óbito, e são pouco que conseguem voltar a sua rotina de vida sem ajudar de familiares ou cuidadores. 
Silva Maia \& Albuquerque Gurgel (2016), descrevem que a intervenção fisioterapêutica do paciente com fratura de fêmur é indicada tanto para a reabilitação, quanto para a prevenção de complicações, não importando se o paciente foi submetido ao tratamento cirúrgico ou ao tratamento conservador. Há necessidade de uma equipe multiprofissional para o adequado acompanhamento e sucesso no tratamento. Fazer com que o indivíduo que sofreu fratura de fêmur tenha uma boa evolução e um acelerado retorno funcional e evitar possíveis complicações, é o objetivo do tratamento fisioterápico.

Carneiro, Alves e Mercadante (2013), comentam que os pacientes sofreram fratura de fêmur, e não voltam ao estado funcional anterior da fratura. Além disso, metade dos idosos que sobrevivem após um ano da fratura, conseguem deambular sem auxílio e as atividades de vida diária são realizadas independentemente por $40 \%$ dos idosos nessa situação. A ausência de deambulação no pós-operatório ocasiona diminuição da força muscular, fazendo com que esses idosos fiquem mais propensos a sofrerem novas quedas, aumentando o risco de nova fratura. É a plausível a ocorrência de uma nova fratura dentro do primeiro ano de recuperação, em uma proporção de 6 a 20 vezes maior que a fratura inicial (ALCANTARA et al., 2020).

Independente do material utilizado na fixação e além disso o tipo de fratura, é recomenda-se que o paciente fique em pé e ande o mais rápido possível, para que ele não desenvolva complicações respiratórias ou outras patologias, relacionadas com a imobilidade no leito. Apesar disso, esse ortostatismo e marcha só é possível se o paciente estiver em bom estado de saúde no geral. O fisioterapeuta ao discorrer no plano de tratamento deve pensar e trabalhar a aptidão aeróbia, pois trabalhando dessa forma ele melhora a aptidão cardiorrespiratória do paciente, aumentando assim sua capacidade de deambulação (CANEIRO; ALVES; MERCADANTE, 2013).

Alguns fatores são descritos por Barreira (2015), para a prevenção de quedas e risco de fraturas de fêmur, como: orientações aos idosos sobre o risco de quedas e suas implicações, avaliar a função cognitiva e consciência dos idosos, avaliar a capacidade de executar as tarefas do dia a dia, avaliar a visão, audição, nutrição e a mobilidade, trabalhar exercícios físicos na fisioterapia como: fortalecimento muscular global, melhora de equilíbrio e treino de marcha, eliminando também as barreiras arquitetônicas. Todos esses aspectos ao lado com a fisioterapia, constituem medidas que promovem a saúde e qualidade de vida do idoso após a fratura de fêmur, evitando novas quedas e recidivas de fratura.

De acordo com Chang et al., (2016), as atividades físicas são essenciais para os desafios e as intervenções para promover a manutenção em longo prazo. Várias intervenções 
de reabilitação têm sido empregadas para ajudar os pacientes com fratura de fêmur a recuperar sua independência funcional. A fisioterapia abre na fase inicial do hospital. Após a alta hospitalar, os pacientes permanecem o programa de reabilitação e são orientados a realização de exercícios em casa, para elevar ao máximo e manter sua recuperação funcional. É um trabalho desafiador, tendo em vista que muitos usuários que têm limitações, ou por causa da dor, medo de cair, ou fatores ambientais externos, como falta de apoio dos familiares em casa.

Para Soares et al., (2014), a fratura proximal do fêmur é a principal causa de morbidade, institucionalização e mortalidade em idosos. E a sua incidência ocorrerá de acordo com os estudos onde haverá um aumento de 1,7 milhões de indivíduos em 1990 para cerca de 6,3 milhões em 2050. A mortalidade é estimada em $24 \%$ até 12 meses após a fratura de quadril. Ainda, um número expressivo desses pacientes não retorna ao estado funcional pré-fratura. Em um ano de pós-operatório, menos de 50\% dos sobreviventes podem andar sem ajuda, e apenas $40 \%$ podem realizar as atividades da vida diária independente de ajuda de terceiros ou familiares.

Já Silva Maia \& Albuquerque Gurgel (2016), comenta que a redução da força muscular diminuída dos pacientes acarretará em uma redução na disposição de deambulação pós-operatória, o que o torna vulnerável a novas quedas e com risco de sofrer uma fratura de quadril contralateral. Alguns estudos relatam que a probabilidade de uma nova fratura é de seis a vinte vezes maior que a fratura inicial no primeiro ano de recuperação. Por este motivo a finalidade da fisioterapia no tratamento pós-operatório dos indivíduos com fratura em fêmur proximal é estimular a força muscular, melhorar a segurança e eficiência da deambulação, fornecendo assim, maior independência ao idoso.

Neto (2017), relata que a fisioterapia no início é de extrema importância para o paciente. O fisioterapeuta tem que ter o conhecimento e habilidade para conhecer os tipos de fraturas, assim como o material usado para fixação cirúrgica. Estes dados vão intervir no procedimento, que inclui o tempo de deambulação, a descarga do peso no membro afetado, bem como restrições em alguns movimentos. as quedas, em sua maioria, podem ser prevenidas e evitadas, diminuindo as consequências, elas podem causar uma redução ou perda da autonomia, do bem-estar, da qualidade de vida, aumentando os danos sociais, financeiros, emocionais e mentais, levando à hospitalização, institucionalização e aumento da morbidade e mortalidade 


\section{CONCLUSÃO}

Promover o envelhecimento saudável da população idosa é um dos grandes desafios da nossa sociedade, são vários fatores que desencadeiam o envelhecimento como sendo um fardo para muitos nessa fase da vida. As quedas são frequentes entre os idosos e produzem complicações que alteram negativamente a qualidade de vida dessas pessoas, afetando tanto fisicamente como psicologicamente, levando muitos a paralisarem suas atividades rotineiras e também a manter o isolamento no meio social.

O tratamento fisioterapêutico pode ser necessário em qualquer fase da vida, porém no idoso tem uma relevância não só de tratamento, mas também de prevenção e intervenção, o que ajuda na melhora da qualidade de vida. Viabilizar a saúde junto aos idosos deve tornar-se um habito constante, por isso, é de suma importância o acompanhamento de um profissional qualificado atuando na terceira idade, promovendo praticas preventivas de exercícios físicos.

Como exercícios de fortalecimento, de equilíbrio e de marcha, ambos trabalhados em sessões de Fisioterapia, as quais levam o aumento da força muscular; melhora o equilíbrio, a flexibilidade, a coordenação motora e a propriocepção, além do ensinamento de exercícios que futuramente poderão ser realizados sozinhos pelo paciente, tornando assim uma vida saudável e prazerosa. Diante desse contexto a atuação do fisioterapeuta na prevenção a quedas durante a terceira idade é extremante importante no ambiente domiciliar. 


\section{REFERÊNCIAS}

ABREU, Débora Regina de Oliveira Moura et al. Fatores associados à recorrência de quedas em uma coorte de idosos. Ciência \& Saúde Coletiva, v. 21, p. 3439-3446, 2016.

ALCANTARA, Carlos et al. Fatores associados ao desfecho da hospitalização de idosos submetidos a correção de fratura de fêmur. Cogitare Enfermagem, v. 25, 2020.

BARREIRA, Elisabete Maria Gomes. Idosos com fratura proximal do fémur. Análise das quedas e alterações funcionais. 2015. Tese de Doutorado.

CARNEIRO, Mariana Barquet; ALVES, Débora Pinheiro Lédio; MERCADANTE, Marcelo Tomanik. Physical therapy in the post-operative of proximal femur fracture in elderly: Literature review. Acta ortopedica brasileira, v. 21, n. 3, p. 175-178, 2013.

CHANG, Feng-Hang et al. Does self-efficacy mediate functional change in older adults participating in an exercise program after hip fracture? A randomized controlled trial. Archives of physical medicine and rehabilitation, v. 96, n. 6, p. 1014-1020. e1, 2015.

CHEHUEN NETO, José Antonio et al. Percepção sobre queda e exposição de idosos a fatores de risco domiciliares. Ciência \& Saúde Coletiva, v. 23, p. 1097-1104, 2018.

FERNANDES, Sabrina Emylle Torres et al.Papel da enfermagem na prevenção de quedas em idoso: uma revisão bibliográfica. Congresso nacional do envelhecimento humano, p.111, jul, 2016.

FREITAS, Mariana Gonçalves de et al. Idosos atendidos em serviços de urgência no Brasil: um estudo para vítimas de quedas e de acidentes de trânsito. Ciência \& Saúde Coletiva, v. 20, p. 701-712, 2015.

GASPAROTTO, Lívia Pimenta Renó; FALSARELLA, Gláucia Regina; COIMBRA, Arlete Maria Valente. As quedas no cenário da velhice: conceitos básicos e atualidades da pesquisa em saúde. Revista Brasileira de Geriatria e Gerontologia, v. 17, n. 1, p. 201-209, 2014.

GOMES, Erika Carla Cavalcanti et al. Fatores associados ao risco de quedas em idosos institucionalizados: uma revisão integrativa. Ciência\&SaúdeColetiva, v. 19, p. 3543-3551, 2014.

KRONBORG, Lise et al. Feasibility of progressive strength training implemented in the acute ward after hip fracture surgery. PloSone, v. 9, n. 4, p. e93332, 2014.

MORSCH, Patricia; MYSKIW, Mauro; MYSKIW, Jociane de Carvalho. A problematização da queda e a identificação dos fatores de risco na narrativa de idosos. Ciência \& Saúde Coletiva, v. 21, p. 3565-3574, 2016.

NETO, AgrimeronAntônio Delmiro Santos et al. Fratura de fêmur em idosos hospitalizados: revisão integrativa. Caderno de Graduação-Ciências Biológicas e da Saúde-UNITALAGOAS, v. 4, n. 2, p. 203, 2017. 
OLIVEIRA, Adriana Sarmento de et al. Environmental hazards and risk of fall in the elderly: systematic review. Revista Brasileira de Geriatria e Gerontologia, v. 17, n. 3, p. 637-645, 2014.

SOARES, Danilo Simoni et al. Fraturas de fêmur em idosos no Brasil: análise espaçotemporal de 2008 a 2012. Cadernos de Saúde Pública, v. 30, p. 2669-2678, 2014.

SILVA MAIA, Francisco Eudison; ALBUQUERQUE GURGEL, Fabio Firmino. Existe fundamento científico para o tratamento da fratura de fêmur pela hidroterapia? Uma revisão integrativa. Revista de Atenção à Saúde, v. 14, n. 49, p. 104-110, 2016.

WOODWARD, Lynda M. et al. Most functional outcomes are similar for men and women after hip fracture: a secondary analysis of the enhancing mobility after hip fracture trial. BMC geriatrics, v. 14, n. 1, p. 140, 2014. 


\section{SOBRE OS AUTORES}

\section{Renilce Rodrigues Ferreira}

Acadêmica em Fisioterapia - Centro universitário do Norte

(UNINORTE), Pesquisadora Junior em Saúde Pública.
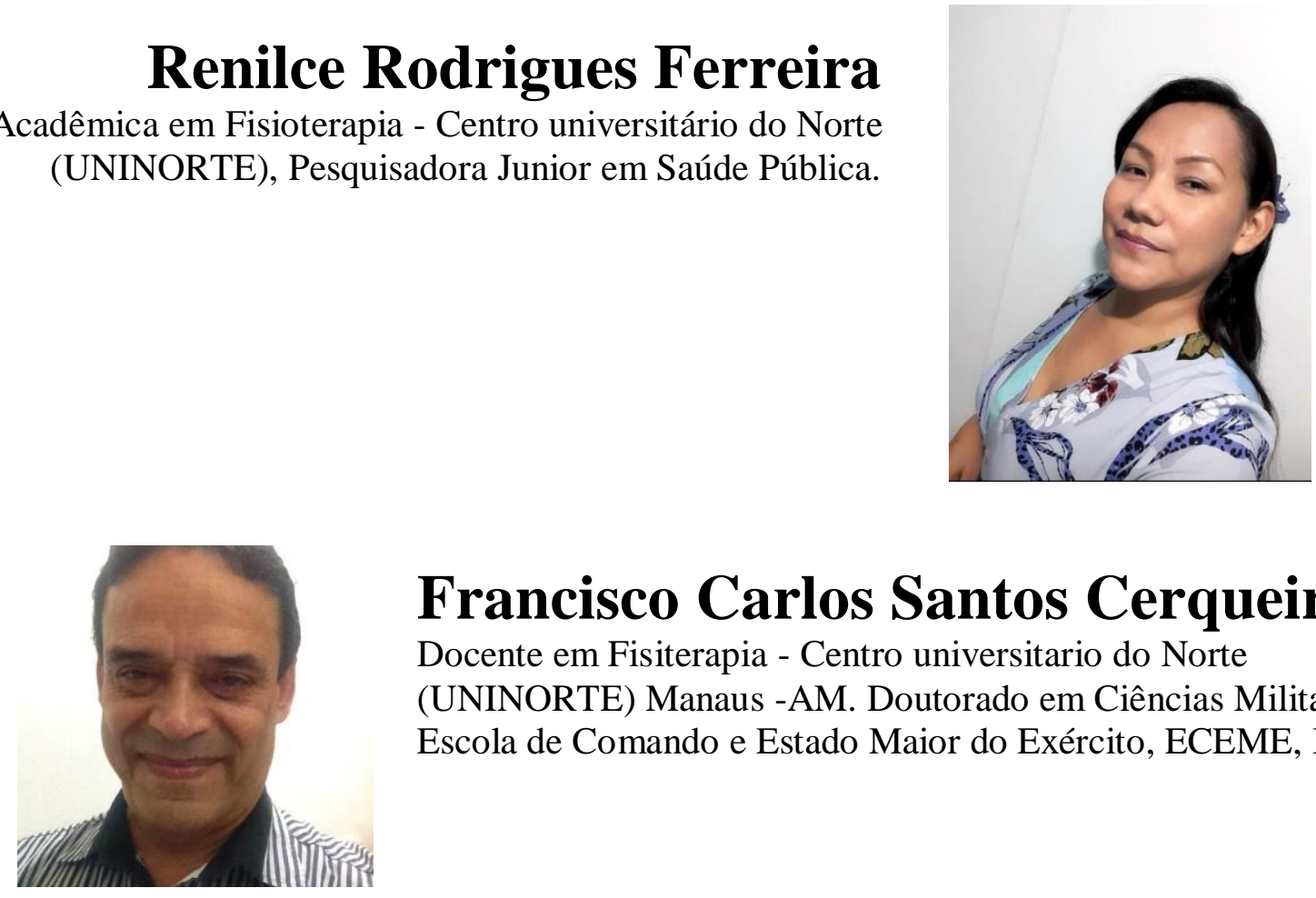

\section{Francisco Carlos Santos Cerqueira}

Docente em Fisiterapia - Centro universitario do Norte

(UNINORTE) Manaus -AM. Doutorado em Ciências Militares.

Escola de Comando e Estado Maior do Exército, ECEME, Brasil.

Michelli Domingos Da Silva

Enfermeira. Doutorra em Saude Pública - Universidad de

CienciasEmpresaliares Y Sociales (UCES) - Argentina.

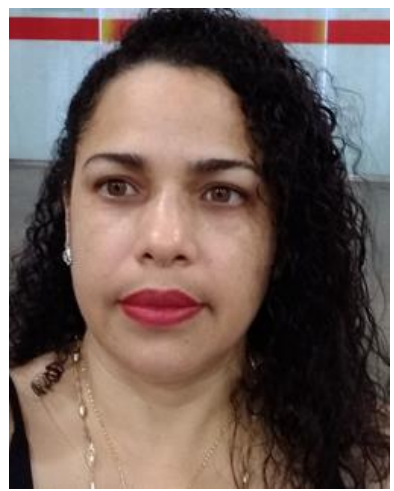


www.editorapublicar.com.br contato@editorapublicar.com.br

@epublicar

facebook.com.br/epublicar

\section{IMPORTÂNCIA DA FISIOTERAPIA NO TRATAMENTO DE FRATURA DE COLO DE FÊMUR EM IDOSOS ACIM/A DE 60 ANOS}

Renilce Rodrigues Ferreira Francisco Carlos Santos Cerqueira 
www.editorapublicar.com.br contato@editorapublicar.com.br

@epublicar

facebook.com.br/epublicar

\section{IMPORTÂNCIA DA FISIOTERAPIA NO TRATAMENTO DE FRATURA DE COLO DE FÊMUR EM IDOSOS ACIMA DE 60 ANOS \\ Renilce Rodrigues Ferreira} Francisco Carlos Santos Cerqueira 